\title{
ESBL-producing Gram-negative organisms in the healthcare environment as a source of genetic material for resistance in human infections
}

\author{
M. Muzslaya, ${ }^{\star}$, G. Moore ${ }^{b}$, N. Alhussainic, A.P.R. Wilson ${ }^{d}$ \\ ${ }^{a}$ Environmental Research Laboratory, University College London Hospitals \\ NHS Foundation Trust, London, UK \\ ${ }^{\mathrm{b}}$ Biosafety, Air and Water Microbiology Group, Public Health England, Porton \\ Down, UK \\ ${ }^{\mathrm{C}}$ Infection and Immunity, University College London, London, UK \\ ${ }^{d}$ Clinical Microbiology and Virology, University College London Hospitals NHS \\ Foundation Trust, London, UK \\ ${ }^{*}$ Corresponding author. Address: Environmental Research Laboratory, \\ University College London Hospitals, Room E -2PT00, EGA Wing Level -2, \\ 235 Euston Road, London, NW1 2BU. Tel: +44 (0) 2034476702 . E-mail: \\ Monika.Muzslay@uclh.nhs.uk
}




\section{SUMMARY}

\section{Background}

The increasing prevalence of extended-spectrum $\beta$-lactamase (ESBL)producing Enterobacteriacae in the healthcare setting and in the community despite established infection control guidelines indicates that these microorganisms may possess survival strategies that allow them to persist in the environment.

\section{Aims}

To determine the extent and variation in endemic ESBL-carrying species in different ward environments.

To investigate the potential for cephalosporin resistance to be transferred from environmental isolates to human pathogens.

\section{Methods}

Conventional microbiological methods were used to sample 1436 environmental surfaces for ESBL-producing bacteria. Transconjugation assays (broth mating experiments) were performed using environmental ESBL-producing isolates as donors and streptomycin-resistant Escherichia coli (NCTC 50237) as the recipient.

\section{Findings}

The prevalence of ESBL-producing bacteria on surfaces in a non-outbreak setting was low $(45 / 1436 ; 3.1 \%)$. The sites most likely to be contaminated were the drains of handwash basins (28/105; $26.7 \%)$ and floors (14/160; $8.8 \%$ ). Fifty-nine ESBL-carrying organisms were isolated. Of these, Klebsiella spp (33.9\%), Enterobacter spp (20.3\%), Pantoea spp (15.3\%) and Citrobacter $\operatorname{spp}(13.6 \%)$, were the most common isolates. ESBL determinants were successfully transferred from three representative environmental isolates (Pantoea calida, Klebsiella oxytoca, Raoultella ornithinolytica) to the human pathogen E. coli.

\section{Conclusion}

ESBL-producing Gram-negative isolates were recovered from the hospital environment in the absence of any ESBL infection on the wards.

The drains of hand wash basins should be considered potential long-term reservoirs of multi-drug resistant bacteria and drug resistance genes. These genes can reside in various genera of hardy environmental organisms and be a potential source of ESBL for more common human pathogens.

\section{Keywords}

Extended-spectrum $\beta$-lactamase-producing bacteria

Environmental contamination

Hospital drains

Pantoea calida

Gene transfer 


\section{Introduction}

With increasing use of broad spectrum antimicrobials and seriously ill patients surviving for longer periods, multidrug resistance (MDR) has significantly increased in the last decade and has emerged as a global concern.

At the same time fewer new antibiotics are becoming available and the World Health Organization has developed a global action plan to tackle antibiotic resistance. ${ }^{1}$ In the United Kingdom (as in the rest of Europe), the rapid evolution and spread of MDR Gram-negative bacteria among hospitalised patients is of particular concern. ${ }^{2,3}$

The increased prevalence of Enterobacteriaceae resistant to extended spectrum cephalosporins has been caused by the circulation of different plasmids containing a diversity of extended spectrum $\beta$-lactamase (blaESBL) genes. ${ }^{4}$ The genes encoding for CTX-M type ESBL enzymes are normally found on the chromosome of Kluyvera species. Kluyvera spp are ubiquitous within the environment (water, soil, hospital sinks) but rarely cause infections in humans. However, they are able to transfer the genes encoding for CTX-M enzymes to other Gram-negative bacteria. ${ }^{5}$ Horizontal gene transfer requires DNA from one cell to be physically transferred to another. The DNA must then be incorporated into the recipient's genome so that it can be stably inherited. Horizontal gene transfer by plasmid mediated conjugation is thought to play an important role in the adaptation of bacteria to various conditions in the clinical environment. ${ }^{6}$

Gram-negative organisms can lose viability rapidly under dry conditions ${ }^{7}$; as such the role of environmental reservoirs in the transmission of ESBL infection is often overlooked. However, most nosocomial pathogens can persist on inanimate surfaces for many weeks ${ }^{8}$ and prolonged environmental survival of carbapenem-resistant Klebsiella pneumoniae and ESBL-producing Escherichia coli has been demonstrated. ${ }^{9,10}$ The surfaces most likely to be contaminated with MDR Gram-negative organisms are those associated with sinks, toilet and shower facilities. ${ }^{11}$ The presence of moisture facilitates bacterial survival and an increasing number of outbreaks have been linked to hospital sinks and taps. ${ }^{12-14}$

This study seeks to determine the extent and variation in ESBL-carrying Gram-negative species in different types of hospital ward environment and to demonstrate the potential pathogenic importance of environmental reservoirs of ESBL-producing bacteria in the transmission of Gram-negative infection in the healthcare setting.

\section{Methods}

\section{Study Setting}

A microbiological survey of 13 different ward environments (located in seven different buildings) was carried out at a UK teaching hospital over a 4 month period. Patients were not screened routinely for carriage of ESBL. Rooms occupied by patients colonised/infected with ESBL-producing 
Enterobacteriacae were not specifically targeted to sample. There was no outbreak during the study.

\section{Environmental Sampling}

Sampling focused on those areas considered most likely to harbour Gramnegative organisms (e.g. sinks; showers) in patient rooms, toilets and bathrooms. Sampling was also performed in non-clinical areas including beverage bays, visitor toilets, staff toilets, changing rooms, sluice rooms, corridors and kitchens on different speciality wards.

A total of 1436 surfaces (1006 clinical; 430 non-clinical) were assessed for contamination with ESBL-producing bacteria (Table I).

Each environmental site was sampled using a non-selective blood agar contact plate (diameter $55 \mathrm{~mm}$; Oxoid, Basingstoke, UK). An R2A agar contact plate (supplemented with $0.5 \%$ Tween and $0.07 \%$ lecithin; diameter $55 \mathrm{~mm}$; Southern Group Limited, Corby, UK) was used to sample an adjacent test area for less fastidious organisms. Cotton swabs, pre-moistened with phosphate-buffered saline (Oxoid), were used to sample two irregular-shaped surfaces (drain and tap aerator). Swabs were directly plated onto Columbia agar with horse blood and R2A agar plates (diameter $90 \mathrm{~mm}$; Oxoid). Blood and R2A agar plates were incubated aerobically at $37^{\circ} \mathrm{C}$ for 48 hours and room temperature for 5-7 days respectively.

\section{Microbiological Analysis}

Presumptive Gram-negative colonies were Gram-stained and tested for their ability to ferment lactose. Presumptive Enterobacteriacae isolates were screened for resistance to cefpodoxime $(10 \mu \mathrm{g})$. Resistant isolates $(\leq 19 \mathrm{~mm}$ zone diameter) ${ }^{15}$ were tested for ESBL and AmpC production (MASTDISCS ${ }^{\mathrm{TM}}$ AmpC and ESBL ID set Mast Group Ltd, Bootle, UK). Organisms demonstrating AmpC activity alone were discarded.

Presumptive $P$. aeruginosa isolates were screened for resistance to ceftazidime $(30 \mu \mathrm{g})$. Resistant isolates were also assessed for ESBL production (MASTDISCS ${ }^{\mathrm{TM}}$ ESBL ceftazidime paired ID).

Identification to species level was performed using the oxidase test and either API 20E or API 20NE biochemical test strips (BioMérieux, Basingstoke, UK). Isolates that did not provide an acceptable profile were identified via Matrix Assisted Laser Desorption/lonisation - Time of Flight (MALDI-TOF) mass spectrometry. All ESBL-producing isolates were sub-cultured and stored at $20^{\circ} \mathrm{C}$ on porous ceramic beads.

\section{Conjugation Assay}

Conjugation assays were performed using a broth mating method ${ }^{16}$ to investigate the transferability of genetic material from environmental isolates to a representative human pathogen. Streptomycin-sensitive ESBL-producing isolates recovered from the ward environment were used as donors and streptomycin resistant E. coli NCTC 50237 (HB101) was used as the recipient. The donor and recipient strains were mixed together at the ratio of 
1:5 (1mL:5mL of cultures of same concentration) respectively in nutrient broth and the suspension incubated overnight at $37^{\circ} \mathrm{C}$. Transconjugants were selected on nutrient agar supplemented with streptomycin $(0.1 \mathrm{~g} / \mathrm{L})$ to inhibit the growth of the donor and ceftazidime $(4 \mathrm{mg} / \mathrm{L})$ (Sigma-Aldrich Ltd., Gillingham, UK) to inhibit the growth of the recipient strain. Recovered colonies were confirmed as E. coli using API 20E. Transconjugants were passaged 15 times on nutrient agar without antibiotics to confirm stability. Each mating experiment was repeated in triplicate.

The recipient, donor and transconjugant isolates were subjected to antibiotic sensitivity testing. The susceptibility to meropenem $(10 \mu \mathrm{g})$, gentamicin (10 $\mu \mathrm{g})$, amikacin $(30 \mu \mathrm{g})$, ciprofloxacin $(1 \mu \mathrm{g})$, piperacillin/tazobactam $(75 / 10 \mu \mathrm{g})$, cefotaxime $(30 \mu \mathrm{g})$, ceftazidime $(30 \mu \mathrm{g})$ and streptomycin $(10 \mu \mathrm{g})$ (Oxoid) was determined according to the criteria established by the British Society for Antimicrobial Chemotherapy (BSAC). ${ }^{15}$

\section{Results}

\section{Microbiological Survey}

ESBL-producing Gram negative isolates were recovered from $45(3.1 \%)$ of the 1436 surfaces sampled (Table I).

ESBL-producing bacteria were not recovered from any of the surfaces sampled in any out-patient clinic $(n=125)$. The wards with the highest number of contaminated sites were a private ward (10.3\%); a haematology ward $(6.5 \%)$ and the intensive care unit (ICU; 6.4\%) (Table II).

Three rooms were occupied by a patient with an ESBL infection; $13.3 \%$ of sites were positive for ESBL-producing bacteria (6/45). In contrast, 2.7\% (37/1391) of sites were positive in areas with no known infected/colonised patient.

The sites most likely to harbour ESBL-producing bacteria were the drain hole of hand wash basins (28/105) and the toilet floor (8/44) (Table I). ESBLcarrying bacteria were not recovered from 16 of 22 sample points on any sampling occasion. These included high-contact sites in patient rooms (e.g. computer keyboard, bed rail, nurse call button), door handles, showers and taps.

More than one species of ESBL-producer was recovered from the same sample point on eleven occasions (Table III). Of the $59 \mathrm{ESBL}$-positive isolates Klebsiella sp. was the most common genus specifically K. pneumoniae $(n=11)$ and $K$. oxytoca $(\mathrm{n}=9)$.

Enterobacter sp. was the second most numerous genus (12 isolates; 20.34\%).

Fifty-two of the 59 ESBL-producing isolates were recovered in patient room (single isolation rooms, bays and patient toilets, bathrooms). Seven isolates were detected within non-clinical areas i.e. a staff toilet, three beverage bays, a kitchen, a reception and a corridor. 
Pantoea calida, a recently described non-human pathogen ${ }^{17}$ was identified via MALDI-TOF and was recovered from the drain of a hand wash basin and from the floors of patient rooms and toilets, beverage bays and staff toilet. $P$. calida was recovered from six different wards located in two different buildings of the hospital.

\section{Conjugation Assay}

Three environmental isolates (Pantoea calida, Klebsiella oxytoca, Raoultella ornithinolytica) were sensitive to streptomycin and were selected as donors. Cephalosporin resistance - co-transferred with gentamicin resistance - was successfully transferred from each donor isolate to $E$. coli.

The antibiotic susceptibility profile of the $15^{\text {th }}$ generation transconjugants remained the same confirming stability of the inheritance (Table IV).

\section{Discussion}

In a non-outbreak setting, the number of surfaces contaminated with ESBLproducing organisms was low (3.1\% of all surfaces sampled). The environment of patients known to be colonised/infected with ESBL-producing Enterobacteriaceae was most likely to be contaminated.

If we had specifically targeted rooms/bays occupied by infected patients, more environmental ESBL-producing organisms may have been detected. Nonetheless, ESBL-producing bacteria were recovered from the ward environment in the absence of infected patients; most commonly from surfaces within a private ward, the ICU and a haematology ward (Table II) Contaminated surfaces contribute to the transmission of hospital pathogens ${ }^{18}$ and whilst some studies suggest that environmental contamination may not play a role in the transmission of ESBL-producing pathogens ${ }^{19}$ others have concluded that admission to a room previously occupied by an infected/colonised patient is a risk factor for acquisition. ${ }^{20}$ The majority of patients admitted to the private ward originated from the Middle East where very high rates of ESBL production among Enterobacteriaceae have been reported ${ }^{21}$ and which may have contributed to the comparatively high surface contamination rate. ESBL- K. pneumoniae was recovered from the toilet floor, toilet seat and a bin lid in a private room three days before the occupying patient (not known to be colonised at the time of sampling) presented with a urinary tract infection. However, ESBL- $K$. pneumoniae was recovered from the clinical sample the isolate was not available for molecular typing and, as such, the similarity between the environmental and clinical isolates could not be determined.

More than one species of ESBL-producing bacteria was recovered from the same environmental site on several occasions, reflecting perhaps the diversity of organisms carried by patients, particularly those in intensive care.

Consumption of antibiotics is also higher in ICUs and exposure of bacteria to sub-therapeutic concentrations can help drive the selection and spread of antibiotic-resistant strains. ${ }^{22}$ It was interesting to note the different isolation 
rate of ESBLs on the two haematology wards environment. Haematology I. (Table II) where the isolation rate was higher (6.5\%) cared for patients with bone marrow transplant for longer admission in single isolation rooms only. Patients on Haematology II were undergoing chemotherapy for shorter admission, stayed in both open bay and single rooms.

ESBL- $P$. calida was recovered from the floor of six different wards located in two different buildings. Both buildings are under the same estate management.

Re-analysis of our environmental strain collection using the MALDI-TOF confirmed that ESBL- $P$. calida had been isolated during previous studies, not only from floors but also from sinks, towel dispensers, door handles and cleaning cloths (unpublished data), suggesting the organism is wellestablished within the hospital microbiome. Persistence within the hospital environment may be due to desiccation-resistance and/or an increased tolerance to disinfectants and, thus, the ability to survive the cleaning process; both can be facilitated by the formation of biofilm. ${ }^{23}$

Drain biofilms harbour large populations of bacteria, ${ }^{24}$ including antibioticresistant strains and hospital sink drains have been implicated in a number of outbreaks of multidrug-resistant bacteria. ${ }^{25-29}$ Our study confirmed that the drain of the handwash basin in patient room is a potential reservoir for ESBLproducing Enterobacteriacae and $P$. aeruginosa. It accounted for $62 \%$ of ESBL-positive sites.

The drains most likely to be contaminated were located in a haematology ward (5/10), the neonatal unit (NNU; 4/8) and the ICU (11/24). However, species diversity differed with ward. Drains located in the NNU were contaminated with an E. cloacae strain, whereas multiple species were recovered from the haematology ward and ICU. For example, ESBL-K. pneumoniae, Citrobacter freundii and Enterobacter asburiae were recovered from a handwash basin located in haematology. Similarly, a single ICU drain harboured ESBL-K. pneumoniae, K. oxytoca and P. aeruginosa.

Eradication of ESBL-producing Enterobacteriacae from sinks is difficult ${ }^{14,29}$ and, consequently, contaminated drains can act as long-term reservoirs of multi-drug resistant bacteria and facilitate the contamination of the ward environment. Studies have demonstrated that drain contents can be dispersed on to surfaces outside of the drain, via splash-back and/or aerosolisation. ${ }^{14,29}$

Many of the environmental bacteria (e.g. Pantoea sp, Raoultella sp.) recovered in our survey rarely cause humans harm. ${ }^{30,31}$ However, they were able to transfer cephalosporin resistance to bacteria that do infect patients. Horizontal gene transfer will happen most frequently in areas of high bacterial density. ${ }^{32}$ Hospital sink drains should be considered a source of antibiotic resistance genes not just a source of antibiotic resistant bacteria.

In this study, surface contamination was detected using culture methods only. The number and type of resistant isolates recovered from the environment could represent a small proportion of the resistant flora in the hospital ecosystem. 
Our study demonstrates that antimicrobial resistance genes could be easily imported from the hospital environmental microbiota and indirectly be disseminated via conjugation with pathogenic species and highlights the potential of hospital waste outlets to act as a reservoir for healthcare-acquired infections caused by ESBL-producing Gram-negative bacteria.

\section{Acknowledgements}

The authors wish to thank Dr Cheryl Collins for supplying the streptomycinresistant Escherichia coli (NCTC 50237) and The Doctors Laboratory (London, UK) for identification of isolates by MALDI-TOF.

\section{Conflict of interest statement}

None declared

\section{Funding sources}

This study was funded by a small grant from the Healthcare Infection Society and A.P.R.W. was part supported by the National Institute for Health

Research University College London Hospitals Biomedical Research Centre. 


\section{References}

1. World Health Organization. Global action plan on antimicrobial resistance. Geneva: WHO; 2015

2. Wilson APR, Livermore DM, Otter JA, et al. Prevention and control of multi-drug-resistant Gram-negative bacteria: recommendations from a Joint Working Party. J Hosp Infect 2016; 92 S1-S44.

3. Cantón R, Akóva M, Carmeli Y, et al. Rapid evolution and spread of carbapenemases among Enterobacteriaceae in Europe. Clin Microbiol Infect 2012; 18:413-431

4. Coque TM, Banquero F, Canton R. Increasing prevalence of ESBLproducing Enterobacteriaceae in Europe. Euro surveill 2008; 13, 47

5. Rossolini GM, D'Andrea MM, Mugnaioli C. The spread of CTX-M-type extended spectrum $\beta$-lactamases. Clin Microbiol Infect 2008; 14: S33S41.

6. Król JE, Nguyen HD, Rogers LM, Beyenal H, Krone SM, Top EM. Increased transfer of a multidrug resistance plasmid in Escherichia coli biofilms at the air-liquid interface. App/ Environ Microbiol 2011; 77: 5079-5088.

7. Hirai Y. Survival of bacteria under dry conditions; from a viewpoint of nosocomial infection. J Hosp Infect 1991; 19: 191-200.

8. Kramer A, Schwebke I, Kampf G. How long do nosocomial pathogens persist on inanimate surfaces? A systematic review. BMC Infect Dis. $2006 ; 16 ; 6: 120$

9. Havill NL, Boyce JM, Otter JA. Extended Survival of CarbapenemResistant Enterobacteriaceae on Dry Surfaces. Infect Control Hosp Epidemiol 2014; 35: 445-447.

10. Starlander $G$, Yin $H$, Edquist $P$, Melhus $\AA$. Survival in the environment is a possible key factor for the expansion of Escherichia coli strains producing extended-spectrum $\beta$-lactamases. APMIS 2014; 122: 59-67.

11. Kac G, Podglajen I, Vaupré S. Colardelle N, Buu-Hoï A, Gutmann L. Molecular epidemiology of extended-spectrum beta-lactamaseproducing Enterobacteriaceae isolated from environmental and clinical specimens in a cardiac surgery intensive care unit. Infect Control Hosp Epidemiol 2004; 25: 852-855.

12. Wendel AF, Kolbe-Busch S, Ressina S, Schulze-Röbbecke $\mathrm{R}$, Kindgen-Milles $\mathrm{D}$, Lorenz $\mathrm{C}$, et al. Detection and termination of an extended low-frequency hospital outbreak of GIM-1-producing Pseudomonas aeruginosa ST111 in Germany. Am J Infect Control 2015; 43: 635-9.

13. Leung GH, Gray TJ, Cheong EY, Haertsch P, Gottlieb T. Persistence of related bla-IMP-4 metallo-beta-lactamase producing

Enterobacteriaceae from clinical and environmental specimens within a burns unit in Australia - a six-year retrospective study. Antimicrob Resist Infect Control 2013; 2: 35.

14. Starlander G, Melhus $\AA$. Minor outbreak of extended-spectrum $\beta$ lactamase-producing Klebsiella pneumoniae in an intensive care unit due to a contaminated sink. J Hosp Infect 2012; 82: 122-4

15. Andrews J. Methods for antimicrobial susceptibility testing. BSAC Version 11.1. May 2012. 
16. Baral P, Neupane S, Marasini BP, Ghimire KR, Lekhak B, Shrestha B. High prevalence of multidrug resistance in bacterial uropathogens from Kathmandu, Nepal. BMC Research Notes 2012, 5:38

17. Popp A, Cleenwerck I, Iversen C, De Vos P, Stephan R. Pantoea gaviniae sp. nov. and Pantoea calida sp. nov., isolated from infant formula and an infant formula production environment. Int J Syst Evol Microbiol 2010; 60: 2786-92.

18. Boyce JM. Environmental contamination makes an important contribution to hospital infection. J Hosp Infect 2007; 65(S2): 50-54

19. Ajao AO, Johnson JK, Harris AD, Zhan M, McGregor JC, Thom KA and Furuno JP. Risk of acquiring extended-spectrum $\beta$-lactamaseproducing Klebsiella species and Escherichia coli from prior room occupants in the intensive care unit. Infect Control Hosp Epidemiol 2013; 34: 453-458

20. Mitchell BG, Dancer SJ, Anderson M, Dehn E. Risk of organism acquisition from prior room occupants: a systematic review and metaanalysis. J Hosp Infect 2015; 91 : 211-217

21. Hawkey PM. Multidrug-resistant Gram-negative bacteria: a product of globalization. J Hosp Infect 2015; 89: 241-247

22. Kümmerer K. Resistance in the environment. J Antimicrob Chemother 2004; 54: 311-320.

23. Espinal P, Martí S, Vila J. Effect of biofilm formation on the survival of Acinetobacter baumannii on dry surfaces. J Hosp Infect 2012; 80: 5660

24. McBain AJ, Bartolo RG, Catrenich CE et al. Microbial characterization of biofilms in domestic drains and the establishment of stable biofilm microcosms. Appl Environ Microbiol 2003; 69: 177-185

25. Hota S, Hirji Z, Stockton K et al. Outbreak of multidrug-resistant Pseudomonas aeruginosa colonization and infection secondary to imperfect intensive care design. Infect Control Hosp Epidemiol 2009; 30: $25-33$

26. Lowe C, Willey B, O'Shaugnessy A et al. Outbreak of extendedspectrum $\beta$-lactamase-producing Klebsiella oxytoca infections associated with contaminated handwashing sinks. Emerg Infect Dis 2012; 18. 1242-1247.

27. Breathnach AS, Cubbon MD, Karunaharan RN, Pope CF, Planche TD. Multidrug-reistant Pseudomonas aeruginosa outbreaks in two hopsitals: association with contaminated hospital waste-water systems. J Hosp Infect 2012; 82: 19-24

28. Kotsanas D, Wijesooriya WRPLI, Korman TM et al. "Down the drain": carbapenem-resistant bacteria in intensive care unit patients and handwashing sinks. MJA 2013; 198: 267-269

29. Roux D, Aubier B, Cochard H, Quentin R, van der Mee-Marquet N. Contaminated sinks in intensive care units: an underestimated source of extended-spectrum beta-lactamase-producing Enterobacteriaceae in the patient environment. J Hosp Infect 2013; 85: 106-111.

30. Fritz S, Cassir N, Noudel R, De La Rosa S, Roche PH, Drancourt M. Postsurgical Pantoea calida meningitis: a case report $J$ Med Case Rep 2014; 8: 195. 
31. Xu M, Xie W, Fu Y, Zhou H, Zhou J. Nosocomial pneumonia caused by carbapenem-resistant Raoultella planticola: a case report and literature review. Infection 2015; 43: 245-8.

32. Sørensen SJ, Bailey M, Hansen LH, Kroer N, Wuertz S. Studying plasmid horizontal transfer in situ: a critical review. Nature Rev Microbiol 2005; 3:700-710. 